\title{
Pengaruh Tegangan Tabung terhadap Kualitas Citra pada Pemeriksaan Computed Tomography Kepala menggunakan Iterative Reconstruction
}

\author{
Muhammad Irsal $^{(1, a)^{*}}$, Nurbaiti $^{(1, b)}$, Aulia Narendra Mukhtar ${ }^{(2, c)}$, Shinta \\ Gunawati $^{(1, \mathrm{~d})}$, Wahyu Hidayat ${ }^{(1, \mathrm{e})}$ \\ (1) Jurusan Teknik Radiodiagnostik dan Radioterapi, Poltekkes Kemenkes Jakarta II, Jakarta Selatan, \\ Indonesia, 12120 \\ (2) Fisikawan Medik, Rumah Sakit Pelabuhan Jakarta, Jakarta Utara, Indonesia, 14260 \\ E-mail: muhammad.irsal@poltekkesjkt2.ac.id
}

Diterima (10 Desember 2020), Direvisi (29 Januari 2021)

\begin{abstract}
Iterative reconstruction can optimize radiation dose and improve image quality on CT scan. This research method is quantitative analytic with the analysis of the results of the head CT examination parameters associated with image quality to changes in variations of $80 \mathrm{kV}, 100 \mathrm{kV}, 120 \mathrm{kV}$ with the use of iterative reconstruction. Image quality measurements are the Hounsfield Unit $(H U)$ value, standard deviation, and Signal to Noise Ratio (SNR) using Radiant Viewers. Effective dose measurement using the Dose Length Product $(D L P)$. Then perform the Kruskal Wallis test to find out whether there is an effect of tube voltage and Iterative Reconstruction on the SNR value using IBM SPSS version 24. The results image quality of the HU value increase due to changes in the $k V$ value, but the value does not change significantly when the iDose changes, for the standard The deviation has decreased due to changes in $k V$, but the value of the value does not experience a significant change at the time of change in iDose, while SNR increases due to changes in $k V$ value and changes in iDose. The percentage ratio of the effective dose in the use of standard $\mathrm{kV}$ with $80 \mathrm{kV}$ decreased radiation dose by $62 \%$, while at $100 \mathrm{kV}$ there was a decrease of $25 \%$, and the use of $120 \mathrm{kV}$ experienced an increase of $25 \%$. The results of the Kruskal Wallis test $p$-value $<0.001$, therefore it can be concluded that there is a difference in the SNR image quality at each change in iDose and $k V$ parameters.
\end{abstract}

Keywords : Effective dose, iterative recinstruction, singal to noise ratio (SNR), tube voltage

Abstrak- Iterative reconstruction mampu mengoptimalkan dosis radiasi dan meningkat kualitas citra pada pemeriksaan CT scan. Metode penelitian ini bersifat kuantitatif analitik dengan analisa parameter hasil pemeriksaan CT kepala yang berhubungan dengan kualitas citra terhadap perubahan variasi $80 \mathrm{kV}, 100 \mathrm{kV}$, $120 \mathrm{kV}$ dengan penggunaan iterative reconstruction. Pengukuran kualitas citra yaitu nilai Housfield Unit (HU), standar deviasi dan Signal to Noise Ratio (SNR) menggunakan Radiant Viewers. Pengukuran dosis efektif dengan menggunakan Dose Length Product (DLP). Kemudian melakukan uji kruskal wallis untuk mengetahui apakah terjadi pengaruh tegangan tabung dan Iterative Reconstruction terhadap niali SNR menggunakan SPSS IBM versi 24 . Hasil kualitas citra nilai $\mathrm{HU}$ meningkat akibat perubahan nilai $\mathrm{kV}$, akan tetapi nilai tidak mengalami perubahan yang signifikan pada saat perubahan iDose, untuk standar deviasi mengalami penurunan akibat perubahan $\mathrm{kV}$, akan tetapi nilai nilai tidak mengalami perubahan yang signifikan pada saat perubahan iDose, sedangkan SNR terjadi peningkatan akibat perubahan nilai $\mathrm{kV}$ maupun perubahan iDose. presentase perbandingan dosis efektif pada penggunaan standar $\mathrm{kV}$ dengan $80 \mathrm{kV}$ mengalami penurunan dosis radiasi sebesar $62 \%$, sedangkan pada $100 \mathrm{kV}$ mengalami penurunan $25 \%$, dan pada penggunaan $120 \mathrm{kV}$ mengalami meningkatkan $25 \%$. Hasil uji kruskal wallis $p$-value $<0,001$, Oleh karena itu dapat disumpulkan bahwa terjadi perbedaan kualitas citra SNR pada setiap perubahan iDose dan parameter $\mathrm{kV}$.

Kata Kunci: Dosis efektif, iterative recinstruction, singal to noise ratio (SNR), tegangan tabung 


\section{PENDAHULUAN}

Penggunaan computed tomography (CT) telah digunakan dalam beberapa pemeriksaan sebagai modalitas untuk mendiagnosa klinis akut, sebagai alat deteksi perubahan nodul dan tumor metastasis, meskipun mulai banyak rumah sakit menyediakan pemeriksaan Magnetic Resonance Imaging (MRI) sebagai salah satu penunjang pencitraan medis [1-4]. CT scan kepala non-kontras adalah pemeriksaan rujukan terbanyak dari unit gawat darurat dimana pasien mengalami cedera kepala, gejala stroke dan trauma pada intracranial [5]. Kecepatan akusisi dan resolusi spasial pada CT mampu mendeskripsikan kualitas citra anatomi pada ukuran kecil (sub millimeter) memberikan banyak informasi diagnostik optimal. Akan tetapi, paparan radiasi yang disebabkan oleh CT menunjukan peningkatan resiko kanker kepada pasien [6-7].

Metode Itarative Recontruction (IR) mulai diterapkan pada CT pada tahun 1960 dan berhasil digunakan pada pemeriksaan klinis untuk pertama kali dengan recontruksi citra berukuran 128 x 128 per metriks citra dan menggunakan citra berukuran 512 x 512 high resolution untuk kegiatan penelitian khusus seperti menilai citra artefak dan noise [17]. pada tahun 2008 perkembangan IR mampu meningkatkan kualitas citra dan dapat mengurangi dosis radiasi pada pemeriksaan klinis CT [18]

Salah satu pemeriksaan CT kepala rujukan dari ruang gawat darurat adalah Mild Head Injury (MHI) atau cedera kepala ringan merupakan salah satu pemeriksaan yang dapat memicu brain concussion atau geger otak. Hal ini dapat terjadi akibat jatuh dari tempat tidur, kursi, meja, tangga atau bahkan tersandung saat berjalan ataupun sedang bermain. MHI menyebabkan infark pada Basal GangliaInternal Capsule (BGIC) [8-10] . Sebagian besar pemeriksaan neurologis memberikan hasil normal, keparahan MHI berhubungan dengan gejala klinis. MHI dapat menyebabkan fraktur, intracranial hemorrhage (ICH), hemorrhagic stroke dan ischemic stroke pada daerah ganglia basalis [11-14] .Cedera kepala telah dikategorikan : ringan, sedang dan berat sesuai dengan tingkat keparahan oleh Glasgow Outcome Scale (GCS [15]. Selain itu, Cranial malformations dan head congenital menunjukkan pencitraan CT mampu mendeteksi dengan baik [16].

Pada pemeriksaan CT kepala optimalisasi dosis radiasi sangat penting, terutama untuk pencegahan terjadinya penyakit katarak akibat radiasi ke organ lensa mata, dan juga pencegahan perkembangan tumor ganas dari organ radiosensitif seperti kelenjar ludah, kelenjar tiroid, dan retina, terutama pada anak-anak. Radiografer bertanggung jawab untuk pemberian dosis radiasi serendah mengkin dengan kualitas citra optimal [6]. Tujuan penurunan dosis adalah sesuai dengan "ALARA" as low as reasonably achievable dengan kualitas gambar optimal. Penyesuaian beberapa parameter utama CT langsung mengurangi dosis radiasi. Menurunkan kilovolt $(\mathrm{kVp})$ dan milliampere-second (mAs) sebagai metode yang efektif untuk mengurangi dosis radiasi dengan menjaga kualitas gambar agar tetap optimal. Pada penelitian oleh Irsal, 2020 penggunaan parameter $\mathrm{kV}$ dapat dioptimalkan untuk mengurangi dosis radiasi dan meningkatkan kualitas citra [19], penurunan dosis radiasi dengan menjaga kualitas gambar agar tetap optimal dengan menggunakan filter, reconstruction kernel dan iterative reconstruction [20]. sehingga peneliti tertarik untuk melakukan analisa pengaruh tegangan tabung terhadap penggunaan iterative reconstruction pada pemeriksaan CT kepala menggunakan pantom antrophomorphic sebagai pengganti pasien pengganti pasien pemeriksaan CT. 


\section{METODE PENELITIAN}

Penelitian menggunakan peralatan pantom antophomorphic kyoto kagaku sebagai organ kepala pengganti pasien dan software Radiant Viewer sebagai analisa pengolahan kualitas citra dan CT scan 64 slice mode helical. Data citra hasil pemeriksaan CT kepala dilakukan ROI (Region of interest) dengan ukuran diameter 3 nilai housfield unit, standar deviasi dan signl to noise ratio (SNR) sebagai parameter kualitas citra pada beberapa organ kepala yaitu cavity orbita dengan jumlah potongan citra sebanyak 10 citra, kemudian lobus frontalis jumlah potongan citra sebanyak 15 citra, selanjutanya lobus occipitalis sebanyak 15 citra, basal ganglia sebanyak 15 citra, sulcus frontalis sebanyak 10 citra dan sulcus interparietal sebanyak 15 citra pada setiap eksposi perubahan tegangan tabung, dengan pemeriksaan CT kepala ditunjukan pada Gambar 1.

Pada Gambar 2 dan Tabel 1. Parameter pengukuran kualitas citra SNR dilakukan agar mengetahui tingkatan informasi citra yang dihasilkan dari signal terhadap noise. Pengukuran SNR menggunakan Persaman 1.

$$
S N R=\frac{\text { mean } H U R O I}{S D H U R O I}
$$

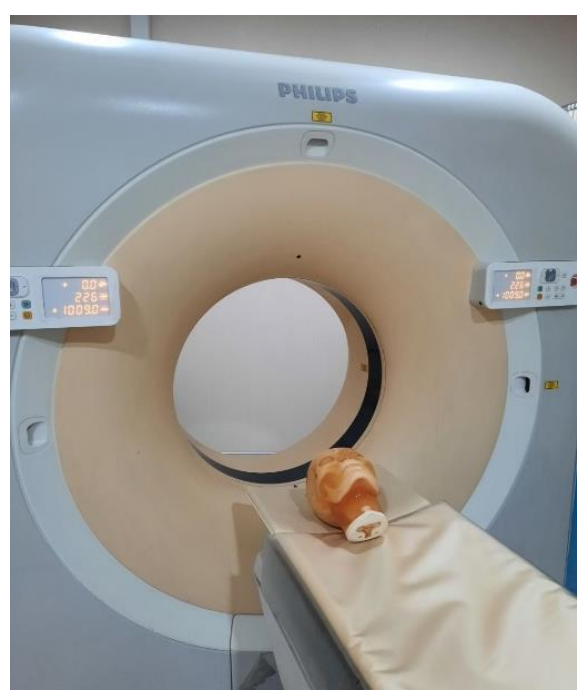

Gambar 1. Pemeriksaan CT dengan pantom

Dalam melakukan estimasi dosis efektif pada pemeriksaan CT kepala, nilai dose lenght product (DLP) dikalikan dengan faktor koreksi $k$ yang diperoleh dari Tabel 2, nilai $k$ merupakan nilai yang dinormalisasi dengan fungsi tegangan tabung pada pesawat CT dengan eksposi menggunakan pantom abdomen dan kepala [21]. Faktor koreksi Pengukuran dosis efektif menggunakan Persamaan 2.

$$
E_{D L P}=k \times D L P
$$

Kemudian melakukan uji kruskal wallis untuk mengetahui apakah terjadi pengaruh tegangan tabung dan Iterative Reconstruction terhadap niali SNR menggunakan SPSS IBM versi 24.

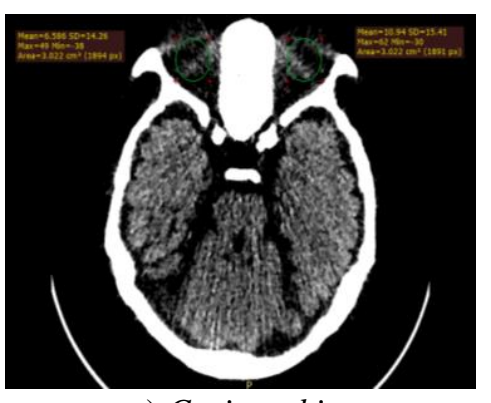

a) Cavity orbita

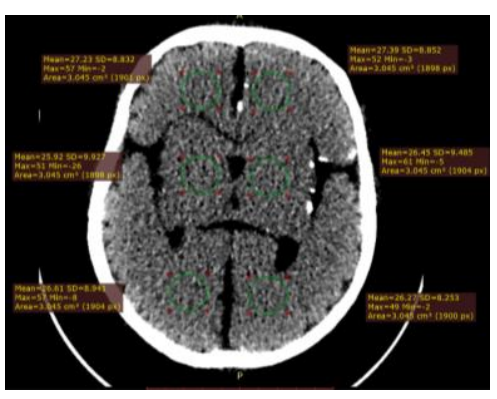

b) lobus frontalis, lobus occipitc basal ganglia

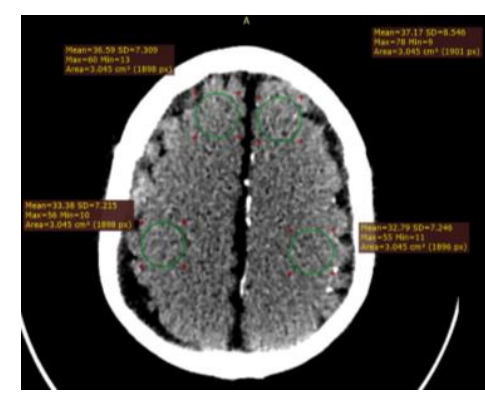

c) sulcus frontalis, sulcus interparietal

Gambar 2. ROI pada citra pemeriksaan CT kepala 
Tabel 1. Paremeter pemeriksaan CT kepala

\begin{tabular}{ccccc}
\hline \multirow{2}{*}{ Parameter } & Protokol CT kepala & \multicolumn{3}{c}{ Iterative reconstrcution } \\
\cline { 3 - 5 } & standar & iDose 1 & iDose 3 & iDose 5 \\
\hline $\mathrm{kV}$ & 120 & $80,100,120$ & $80,100,120$ & $80,100,120$ \\
$\mathrm{mAs}$ & 180 & 200 & 200 & 200 \\
Pitch & 0,276 & 0,276 & 0,276 & 0,276 \\
Colimation & $40 \mathrm{~cm} \times 0.625 \mathrm{~cm}$ & $40 \mathrm{~cm} \mathrm{x} 0.625 \mathrm{~cm}$ & $40 \mathrm{~cm} \mathrm{x} 0.625 \mathrm{~cm}$ & $40 \mathrm{~cm} \mathrm{x} 0.625 \mathrm{~cm}$ \\
Rotation time & 0,4 & 0,4 & 0,4 & 0,4 \\
Scan time & 12,1 & 12,1 & 12,1 & 12,1 \\
Slice thicness & 1,5 & 1,5 & 1,5 & 1,5 \\
Recon & iDose 3 & - & - & - \\
Doseright & Ya & Tidak & Tidak & Tidak \\
\hline
\end{tabular}

Tabel 2. faktor koreksi

\begin{tabular}{cc}
\hline Tegangan tabung $(\mathrm{kV})$ & $\begin{array}{c}\text { ICRP 103 } \\
\text { Organ kepala }\end{array}$ \\
\hline 80 & 0,0018 \\
100 & 0,0019 \\
120 & 0,0019 \\
140 & 0,0019 \\
Rerata & 0,0019 \\
\hline
\end{tabular}

\section{HASIL DAN PEMBAHASAN}

Pada penggunaan variasi parameter $\mathrm{kV}$ dilakukan sebanyak $80 \mathrm{kV}, 100 \mathrm{kV}$, $120 \mathrm{kV}$, terhadap penggunaan iterative reconstruction iDose1, iDose 3 , iDose5 dengan metode pemeriksaan ditampilkan pada Gambar 2. Sebelumnya mempertimbangkan parameter protocol CT kepala standar yang telah ditetapak didalam CT scan Phililps Ingenuity dengan perbandingan protokol pada Tabel 1.

Gambar 3 menjelaskan kualitas citra CT pada pemilihan parameter protokol yang digunakan pada pemeriksaan CT kepala terhadap variasi $\mathrm{kV}$ dan iDose, kemudian nilai minimum HU 26,38 $\pm 2,06$ pada $80 \mathrm{kV}$ pada iDose3, standar deviasi $5,33 \pm 0,59$ pada $120 \mathrm{kV}$ pada iDose5, nilai SNR 2,39 $\pm 0,12$ pada $80 \mathrm{kV}$ pada iDose1. Nilai maksimum HU 36,88 $\pm 0,85$ pada $120 \mathrm{kV}$ pada iDose5, standar deviasi $14,03 \pm 0,76$ pada $80 \mathrm{kV}$ pada iDose 1 , nilai SNR 8,20 $\pm 0,7$ pada $120 \mathrm{kV}$ pada iDose5. Dari Gambar 3 menjelaskan bahwa nilai HU meningkat akibat perubahan nilai $\mathrm{kV}$, akan tetapi tidak mengalami perubahan yang signifikan pada saat perubahan iDose. Kemudian untuk pada nilai standar deviasi mengalami penurunan akibat perubahan $\mathrm{kV}$, akan tetapi nilai nilai tidak mengalami perubahan yang signifikan pada saat perubahan iDose terhadap $\mathrm{kV}$. Untuk parameter kualitas citra SNR terjadi peningkatan akibat perubahan nilai $\mathrm{kV}$ maupun perubahan iDose.

Dari hasil analisa pengaruh tegangan tabung terhadap kualitas citra SNR menggunakan iterative recontruction menjelaskan bahwa kualitas citra nilai $\mathrm{HU}$ meningkat akibat perubahan nilai $\mathrm{kV}$, akan tetapi nilai tidak mengalami perubahan yang signifikan pada saat perubahan iDose terhadap $\mathrm{kV}$. Kemudian untuk pada kualitas citra nilai standar deviasi mengalami penurunan akibat perubahan $\mathrm{kV}$, akan tetapi nilai nilai tidak mengalami perubahan yang signifikan pada saat perubahan iDose terhadap $\mathrm{kV}$. Untuk parameter kualitas citra SNR terjadi peningkatan akibat perubahan nilai $\mathrm{kV}$ maupun perubahan iDose. Penentuan optimisasi dalam protokol pemeriksaan CT kepala dapat menggunakan pengukuran 


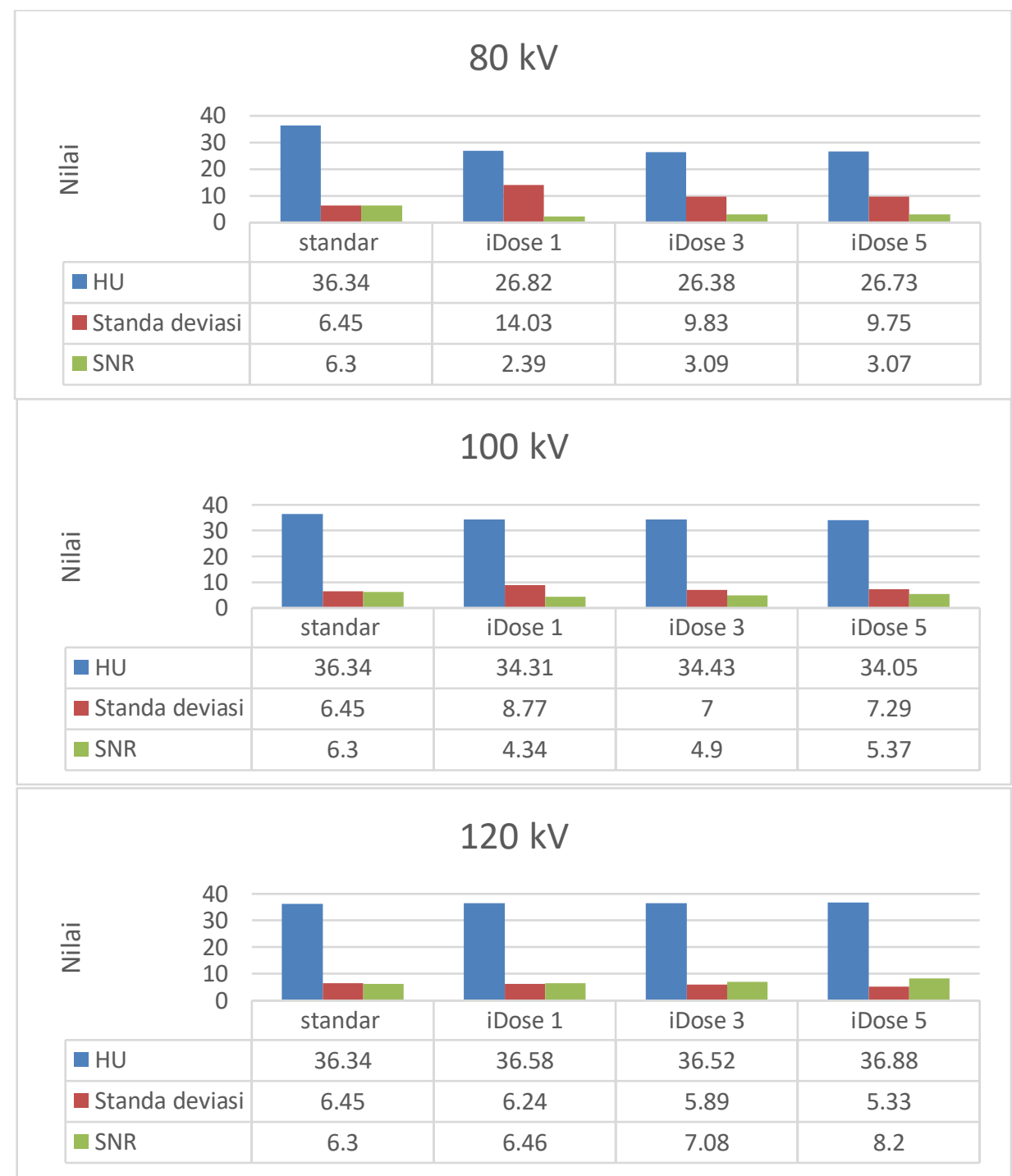

Gambar 3. Perbandingan kualitas citra pada variasi $\mathrm{kV}$ terhadap perubahan iDose

kualitas citra SNR, dimana dengan meningkatnya nillai SNR maka dipastikan bahwa citra radiografi mengalami kenaikan kualitas dengan penurunan niali noise yang akan menyebabkan menurunnya kualitas citra, akan tetapi dalam peningkatan nilai SNR maka dipastikan akan meningkatkan parameter $\mathrm{kV}$ dan mAs. oleh karena itu diperlukan upaya optimasi dengan selalu mempertimbangkan dosis radiasi, anatomi klinis, penggunaan parameter $\mathrm{kV}$ atau $\mathrm{mAs}$ dan juga umur pasien. selain itu sebaiknya dalam penggunaannya protokol pemeriksaan CT akan lebih bila dikombinasikan dengan penggunaan Tube current modulation (TCM) atau pada alat
CT Philips disebut dengan doseright, pada perkembangnya modalitas CT telah menggunakan TCM sebagai salah satu upaya penurunan dosis radiasi dan peningkatan kualitas citra. Dalam penggunaannya TCM akan dengan automatis mengatur parameter mAs mengikuti tebal objek, sehingga dapat menyesuaikan dan lebih efesien dalam menghasilkan dosis radiasi [22].

Pada perhitungan nilai dosis efektif menggunakan nilai Dose lenght product (DLP) menggunakan persamaan faktor koreksi (2) yang ditunjukkan pada Tabel 3. 
Tabel 3. Dosis efektif

\begin{tabular}{ll}
\hline Parameter kV & Dosis efektif $(\mathrm{mSv})$ \\
\hline Standar kV & 0,783 \\
$80 \mathrm{kV}$ & 0,294 \\
$100 \mathrm{kV}$ & 0,590 \\
$120 \mathrm{kV}$ & 0,974 \\
\hline
\end{tabular}

Berdasarkan Tabel 3 dapat kita analisa bahwa penggunaan $\mathrm{kV}$ yang lebih rendah dengan nilai $m A s$ yang konstan dapat menurunkan dosis radiasi. Dengan persentase perbandingan penggunaan standar $\mathrm{kV}$ dengan $80 \mathrm{kV}$ yaitu menurun $62 \%$, sedangkan pada $100 \mathrm{kV}$ menurun $25 \%$, dan pada penggunaan $120 \mathrm{kV}$ meningkatkan $25 \%$ seperti yang ditunjukan pada Gambar 4. Oleh karena itu dibutuhkan pemilihan $\mathrm{kV}$ yang optimal, dengan mempertimbangkan kaulitas citra yang dihasilkan.

Data hasil pengukuran kualitas SNR kemudian dilakukan analisa uji kruskal wallis untuk mengetahui adakah perbedaan nilai SNR terhadap perubahan penggunaan iDose dan parameter $\mathrm{kV}$ yang ditunjukan pada Tabel 4, dimana sampel data yang digunakan untuk mengetahui perbedaan nilai SNR terhadap penggunaan iDose dilakukan pada pemeriksaan CT kepala pada penggunaan parameter $100 \mathrm{kV}$ dengan variasi penggunaan iDose1, iDose3 dan iDose5. Dimana dari hasil uji kruskal wallis nilai $p$-value $<0,001$.

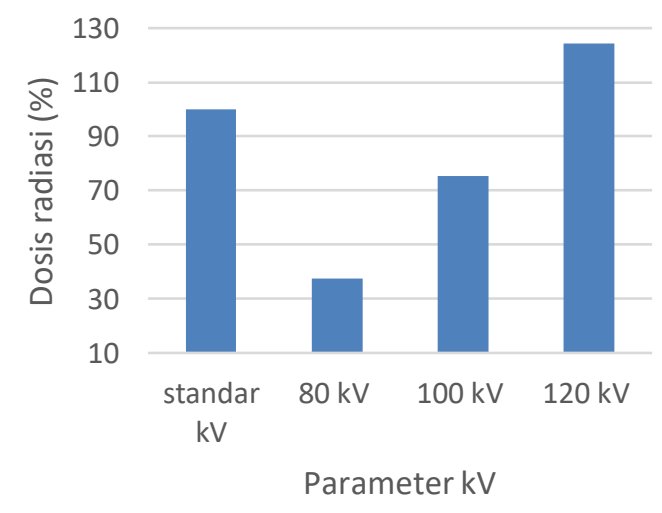

Gambar 4. Presentase dosis efektf pada kenaikan parameter $\mathrm{kV}$
Tabel 4. Uji kruskal wallis

\begin{tabular}{cc}
\hline Parameter & p-value \\
\hline Variasi iDose terhadap SNR & $<0,001$ \\
Variasi kV terhadap SNR & $<0,001$ \\
\hline
\end{tabular}

Untuk mengetahui perbedaan nilai SNR terhadap penggunaan parameter $\mathrm{kV}$ dilakukan pada pemeriksaan CT kepala pada penggunaan iDose 3 dengan variasi penggunaan parameter $80 \mathrm{kV}, 100 \mathrm{kV}$ dan $120 \mathrm{Kv}$. Dimana dari hasil uji kruskal wallis nilai $p$-value $<0,001$. Oleh karena itu dapat disimpulkan bahwa terjadi perbedaan kualitas citra SNR pada setiap perubahan iDose dan parameter Kv.

\section{KESIMPULAN}

Nilai HU meningkat akibat perubahan nilai $\mathrm{kV}$, akan tetapi nilai tidak mengalami perubahan yang signifikan pada saat perubahan iDose terhadap $\mathrm{kV}$, nilai standar deviasi mengalami penurunan akibat perubahan $\mathrm{kV}$, akan tetapi nilai nilai tidak mengalami perubahan yang signifikan pada saat perubahan iDose, SNR terjadi peningkatan akibat perubahan nilai $\mathrm{kV}$ maupun perubahan iDose. Persentase perbandingan pada penggunaan standar $\mathrm{kV}$ dengan $80 \mathrm{kV}$ mengalami penurunan dosis radiasi sebesar $62 \%$, sedangkan pada 100 $\mathrm{kV}$ mengalami penurunan $25 \%$, dan pada penggunaan $120 \mathrm{kV}$ mengalami meningkatkan 25\%. Hasil uji kruskal wallis nilai $p$-value $<0,001$, kemudian untuk mengetahui perbedaan nilai SNR terhadap penggunaan parameter $\mathrm{kV}$ dilakukan pada pemeriksaan CT kepala pada penggunaan iDose 3 dengan variasi penggunaan parameter $80 \mathrm{kV}, 100 \mathrm{kV}, 120$ $\mathrm{kV}$. Dimana dari hasil uji kruskal wallis nilai $p$-value $<0,001$. Oleh karena itu dapat disimpulkan bahwa terjadi perbedaan kualitas citra SNR pada setiap perubahan iDose dan parameter $\mathrm{kV}$. 


\section{UCAPAN TERIMA KASIH}

Ucapatan terima kasih ditujukan kepada Poltekkes Kemenkes Jakarta II yang telah mendanai penelitian melalui dana DIPA Poltekkes Kemenkes Jakarta II Tahun 2020.

\section{DAFTAR PUSTAKA}

R. Hu, A. Padole, dan R. Gupta, "Dual-Energy Computed Tomographic Applications for Differentiation of Intracranial Hemorrhage, Calcium, and Iodine", Neuroimaging Clinics of North America. 2017.

[2] J. Oh, G. Kim, J. Lee, M. Cheon, Y. Park, S. Kim, J. Yi, dan H. Y. Lee, "Automated Detection of Bone Metastatic Changes Using Serial CT scans," Comput. Med. Imaging Graph., vol. 58, pp. 62-74, 2017.

[3] A. Patel, B. van Ginneken, F. J. A. Meijer, E. J. van Dijk, M. Prokop, dan R. Manniesing, "Robust cranial Cavity Segmentation in CT and CT Perfusion Images of Trauma and Suspected Stroke Patients", Med. Image Anal., vol. 36, pp. 216-228, 2017.

[4] J. Berger-groch, D. M. Theisen, D. Ntalos, L. G. Grossterlinden, E. Hesse, F. Fensky, dan M. J. Hartel, "Determination of Bone Density in Patients with Sacral Fractures via CT scan," pp. 5-9, 2018.

[5] S. Chilamkurthy, R. Ghost, S. Tanamala, M. Biviji, N. G. Campeau, V. K. Venugopal, V. Mahajan, P. Rao, dan P. Warier, "Deep Learning Algorithms for Detection of Critical Findings in Head CT Scans: A Retrospective Study", Lancet, vol. 392, no. 10162, pp. 2388-2396, 2018.

[6] H. Almohiy, E. Mohamed, M. Alasar, dan C. Saade, "Correct
Patient Centering Increases Image Quality without Concomitant Increase of Radiation Dose during Adult Intracranial Computed Tomography", J. Med. Imaging Radiat. Sci., pp. 1-8, 2016.

[7] R. Hinzpeter, K. Sprengel, G. A. Wanner, P. Mildenberger, dan $\mathrm{H}$. Alkadhi, "Repeated CT Scans in Trauma Transfers: An Analysis of Indications, Radiation Dose Exposure, and Costs," Eur. J. Radiol., vol. 88, pp. 135-140, 2017.

[8] G. Wang, Y. Luan, L. Feng, dan J. $\mathrm{Yu}$, "Current Status of Infarction in the Basal Ganglia-Internal capsule Due to Mild Head Injury in Children Using PRISMA guidelines (Review)", Exp. Ther. Med., 2019.

[9] C. L. Chang dan N. C. Chiu, "Letter to the Editor Regarding 'Stroke After Minor Head Trauma in Infants and Young Children With Basal Ganglia Calcification: A Lenticulostriate Vasculopathy", $J$. Child Neurol., vol. 33, no. 8, pp. 554-555, 2018.

[10] J. S. Goraya, S. Berry, K. Saggar, dan A. Ahluwalia, "Stroke After Minor Head Trauma in Infants and Young Children With Basal Ganglia Calcification: A Lenticulostriate Vasculopathy", J. Child Neurol., vol. 33, no. 2, pp. 146-152, 2018.

[11] A. Balachandran, S. Kalyanshettar, S. Patil, dan V. Shegji, "Ischemic Stroke in Confederation with Trivial Head Trauma", Case Rep. Pediatr., vol. 2016, pp. 1-4, 2016.

[12] A. Faried, D. Halim, I. A. Widjaya, R. F. Badri, S. F. Sulaiman, and M. Z. Arifin, "Correlation Between The Skull Base Fracture and The Incidence of Intracranial Hemorrhage in Patients with Traumatic Brain Injury", Chinese J. Traumatol. - English Ed., vol. 22, no. 5, pp. 286-289, 2019. 
[13] V. Montalvan, A. Ulrich, S. Wahlster, dan D. Galindo, "Arterial Dissection as a Cause of Intracranial Stenosis: A Narrative Review," Clin. Neurol. Neurosurg., vol. 190, no. December 2019, 2020.

[14] S. P. Toelle, T. Avetisyan, N. Kuyumjyan, B. Sukhudyan, E. Boltshauser, dan A. Hackenberg, "Infantile Basal Ganglia Stroke after Mild Head Trauma Associated with Mineralizing Angiopathy of Lenticulostriate Arteries: An under Recognized Entity", Neuropediatrics, vol. 49, no. 4, pp. 262-268, 2018.

[15] Z. Li, F. Xu, Y. Li, R. Wang, Z. Zhang, dan Y. Qu, "Assessment of Intracranial Pressure Monitoring in Patients with Moderate Traumatic Brain Injury: A Retrospective Cohort Study", Clin. Neurol. Neurosurg., 2020.

[16] J. D. Vargo, A. Hasan, dan B. T. Andrews, "Identification and Management of Cranial Anomalies in Perinatology," Clinics in Perinatology. 2018.

[17] M. Beister, D. Kolditz, dan W. A. Kalender, "Iterative Reconstruction Methods in X-ray CT", Phys. Medica, vol. 28, no. 2, pp. 94-108, 2012.

[18] A. Löve, M. L. Olsson, R. Siemund,
F. Stålhammar, I. M. BjörkmanBurtscher, dan M. Söderberg, "Six Iterative Reconstruction Algorithms in Brain CT: A Phantom Study on Image Quality at Different Radiation Dose Levels", $B r$. J. Radiol., vol. 86, no. 1031, 2013.

[19] M. Irsal, Nurbaiti, A. N. Mukhtar, A. Jauhari, dan G. Winarno, "Variation $\mathrm{kVp}$ and $\mathrm{mAs}$ on $\mathrm{CT}$ Scan Image Quality Using Standard Phantom", AIP Conf. Proc., vol. 2296, no. November, 2020.

[20] H. Yabuuchi, T. Kamitani, K. Sagiyama, Y. Yamasaki, Y. Matsuras, T. Hino, S. Tsutsui, M. Kondo, T. Shirasaka, dan H. Honda, "Clinical Application of Radiation Dose Reduction for Head and Neck CT," European Journal of Radiology. 2018.

[21] P. D. Deak, Y. Smal, dan W. A. Kalender, "Multisection CT Protocols : Sex- and Age-specifi c Conversion Dose from Dose-Length Product", Radiology, vol. 257, no. 1, pp. 158-166, 2010.

[22] M. Irsal dan W. Guntur, "Pengaruh parameter Milliampere-Second (mAs) terhadap Kualitas Citra Dan Dosis Radiasi Pada Pemeriksaan Computed Tomography (CT) scan Kepala Pediatrik," J. Fis. Flux, vol. 17, no. 1, pp. 1-8, 2020. 